\title{
Lactococcus lactis LM0230 contains a single aminotransferase involved in aspartate biosynthesis, which is essential for growth in milk
}

\author{
Edward G. Dudley ${ }^{1}$ and James L. Steele ${ }^{2}$
}

Author for correspondence: James L. Steele. Tel: +1 608262 5960. Fax: +1 6082626872. e-mail: jlsteele@facstaff.wisc.edu

1 Department of Bacteriology, University of Wisconsin-Madison, 1550 Linden Drive, Madison, WI 53706, USA

2 Department of Food Science, University of Wisconsin-Madison, 1605 Linden Drive, Madison, WI 53706, USA

\begin{abstract}
Amino acid aminotransferases (ATases), which catalyse the last biosynthetic step of many amino acids, may have important physiological functions in Lactococcus lactis during growth in milk. In this study, the aspartate ATase gene (aspC) from L. lactis LM0230 was cloned by complementation into Escherichia coli DL39. One chromosomal fragment putatively encoding aspC was partially sequenced. A $\mathbf{1 1 7 9}$ bp ORF was identified which could encode for a 393 aa, 43.2 kDa protein. The deduced amino acid sequence had high identity to other AspC sequences in GenBank and is a member of the $I \gamma$ family of ATases. Substrate-specificity studies suggested that the lactococcal AspC has ATase activity only with aspartic acid (Asp). An internal deletion was introduced into the $L$. lactis chromosomal copy of aspC by homologous recombination. The wild-type and mutant strain grew similarly in defined media containing all 20 amino acids and did not grow in minimal media unless supplemented with asparagine (Asn). The mutant strain was also unable to grow in or significantly acidify milk unless supplemented with Asp or Asn. These results suggest that only one lactococcal ATase is involved in the conversion of oxaloacetate to Asp, and Asp biosynthesis is required for the growth of $L$. lactis LM0230 in milk.
\end{abstract}

Keywords: Lactococcus lactis, lactic acid bacteria, aspartate aminotransferase, amino acid biosynthesis, aspartate biosynthesis

\section{INTRODUCTION}

Lactococcus lactis is widely used by the dairy industry for the manufacture of fermented milk products. The primary role of L. lactis during dairy fermentations is the production of lactic acid from the milk sugar lactose. Additionally, in bacterial ripened cheese varieties where the product may be aged for several months, bacterial enzymes are important for the generation of compounds involved in cheese flavour development (Urbach, 1995).

Strains of $L$. lactis used by the dairy industry are

Abbreviations: Ap, ampicillin; ATase, aminotransferase; CFE, cell-free extract; Em, erythromycin; Opp, Lactococcus lactis oligopeptide transport system.

The GenBank accession number for the sequence reported in this paper is AF035157 auxotrophic for a number of amino acids. The specific amino acid requirements are strain specific (Chopin, 1993) but generally include isoleucine, valine, leucine, histidine and methionine. Bovine milk is on average $3.6 \%$ protein by weight and the majority of the nitrogen exists as $>11 \mathrm{kDa}$ proteins called caseins (Swaisgood, 1985). The non-protein nitrogen (free amino acids and small peptides) fraction of milk is not sufficient to support the growth of lactococci in milk to high cell densities (Juillard et al., 1995a). Therefore, industrially important L. lactis strains contain a number of proteolytic and peptidolytic enzymes to liberate amino acids from milk caseins.

The proteolytic pathway of L. lactis is a well characterized metabolic system consisting of (at least) a cellenvelope associated proteinase (PrtP) and twelve intracellular peptidases (for a recent review see Christensen et al., 1999). Additionally, a broad specif- 
icity oligopeptide transport system (Opp; Tynkkynen et al., 1993), two transport systems for di- and tripeptides (Foucaud et al., 1995; Hagting et al., 1994) and at least nine different amino acid transport systems (Poolman, 1993) have been described. Mutants deficient in PrtP and/or Opp have been used to demonstrate that lactococcal strains that are unable to liberate and/or transport casein-derived oligopeptides only achieve $2-10 \%$ the final c.f.u. $\mathrm{ml}^{-1}$ in milk compared to $\operatorname{PrtP}^{+}$ $\mathrm{Opp}^{+}$strains (Juillard et al., 1995a). This suggests free amino acids and oligopeptides initially present in milk do not contribute significantly to the overall growth of $L$. lactis. In vitro data suggests that lactococci can obtain all amino acids through hydrolysis and transport of $\beta$ casein-derived oligopeptides (Juillard et al., 1995b). However, more recent in vivo studies have shown that lactococci utilize only a limited number of oligopeptides derived from the C-terminal end of $\beta$-casein (Kunji et al., 1998).

It is clear that PrtP and Opp are indispensable for growth of lactococci in milk to high cell densities, and that the rate of hydrolysis of caseins by PrtP is growthrate limiting (Bruinenberg et al., 1992; Juillard et al., 1995a; Helinck et al., 1997). However, the importance of de novo amino acid biosynthesis for optimal growth cannot be excluded. In previous work, a L. lactis aspartic acid (Asp) auxotroph was isolated that acidified milk at a reduced rate compared to the wild-type strain (Wang et al., 1998, 2000). The molecular basis of the mutation(s) in this strain, which was derived by acriflavine mutagenesis, has not been reported. A mutant strain carrying a plasmid copy of the lactococcal pyruvate carboxylase gene, which is probably involved in Asp biosynthesis, acidified milk faster than the strain lacking this plasmid. However, the acidification rate of this plasmid-carrying mutant strain was still different to that of the parent strain containing the vector alone. Therefore, the construction of isogenic strains is necessary to clarify the importance of Asp biosynthesis during growth of L. lactis in milk.

Our laboratory has been studying amino acid aminotransferases (ATases) from L. lactis, with particular focus on their role in amino acid catabolism (Gao et al., 1997, 1998; Atiles et al., 2000). ATases also catalyse the last biosynthetic step of many amino acids. Therefore, we are also interested in creating ATase mutants, identifying the amino acid biosynthetic pathways affected and determining whether the diminished ability of $L$. lactis to synthesize specific amino acids affects this organism's growth in milk. This paper describes the cloning and characterization of the aspartate ATase (aspC) gene of L. lactis LM0230 and the demonstration that strains lacking this gene are unable to synthesize the amino acids Asp or asparagine (Asn). Additionally, the mutant strain was unable to grow in milk, suggesting neither naturally present amino acids and peptides nor oligopeptides liberated from caseins by PrtP and transported by Opp are capable of fulfilling the Asp or Asn requirement of L. lactis.

\section{METHODS}

Bacterial strains, media and plasmids. The bacteria and plasmids used in this study are listed in Table 1 . All cultures were maintained at $-80{ }^{\circ} \mathrm{C}$ in $6.9 \%(\mathrm{w} / \mathrm{v})$ non-fat dry milk and $10 \%(\mathrm{v} / \mathrm{v})$ glycerol. Escherichia coli strains were routinely grown in Luria-Bertani (LB; Sambrook et al., 1989) medium at $37^{\circ} \mathrm{C}$ with aeration. M9 medium (Gerhardt et al., 1994) was prepared containing all 20 common amino acids at $50 \mu \mathrm{g} \mathrm{ml}^{-1}$ except where stated. Additionally, M9 medium was supplemented with $20 \mu \mathrm{g}$ adenine, guanine, uracil and xanthine $\mathrm{ml}^{-1}$. L. lactis LM0230 was routinely grown at $30{ }^{\circ} \mathrm{C}$ in $\mathrm{M} 17$ (Terzaghi \& Sandine, 1975) supplemented with $0.5 \%$ (w/v) glucose (M17-G) or lactose (M17-L). The medium of Gao et al. (1997) containing all 20 amino acids (Asp and Asn both at $0 \cdot 1 \mathrm{~g} \mathrm{l}^{-1}$ ) was used for defined medium (DM) growth experiments. The minimal medium MS15 (Cocaign-Bousquet et al., 1995), containing the amino acids arginine, glutamate, histidine, isoleucine, leucine, methionine, serine, threonine and valine, was modified as described by Wang et al. (1998). Prior to inoculating minimal media, $2 \mathrm{ml}$ aliquots of cells from early stationary phase growth in M17-L were harvested by centrifugation, washed twice with $1 \mathrm{ml} 0.85 \%$ (w/v) $\mathrm{NaCl}$ and resuspended in $1 \mathrm{ml} 0 \cdot 85 \% \mathrm{NaCl}$. This cell suspension was used to inoculate MS15 at an initial $\mathrm{OD}_{600}$ of $0 \cdot 10$ as determined using a Beckman-Coulter DU-65 spectrophotometer. Skimmed milk for growth studies was purchased from the University of Wisconsin-Madison Dairy Plant and was steamed for $20 \mathrm{~min}$, incubated at $30^{\circ} \mathrm{C}$ for $2 \mathrm{~h}$ and steamed again for $20 \mathrm{~min}$ prior to inoculation. For some experiments,

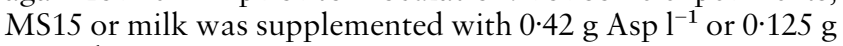
Asn $1^{-1}$. When growing Escherichia coli or L. lactis strains containing pTRKL2-based plasmids, erythromycin (Em) (Sigma-Aldrich) was added to media to a final concentration of $500 \mu \mathrm{g} \mathrm{ml}^{-1}$ or $2 \mu \mathrm{g} \mathrm{ml}^{-1}$, respectively. To select for E. coli strains carrying $\mathrm{pMOB}$ and its derivatives, ampicillin (Ap) was added to media to a final concentration of $60 \mu \mathrm{g} \mathrm{ml}^{-1}$. $L$. lactis strains carrying pJK550 were screened on bromocresol purple/lactose indicator plates (McKay et al., 1973). For experiments using $\alpha$-complementation, IPTG (Promega) and $\mathrm{X}-\mathrm{Gal}$ (Life Technologies) were incorporated into agar media at concentrations of $120 \mu \mathrm{g} \mathrm{ml}^{-1}$ and $20 \mu \mathrm{g} \mathrm{ml}^{-1}$, respectively.

Molecular biology techniques. Recombinant DNA and plasmid isolation techniques were performed as described by Sambrook et al. (1989). Calf intestinal alkaline phosphatase (Promega), T4 DNA ligase (Life Technologies) and restriction enzymes (Life Technologies) were used as recommended by the manufacturer. All DNA primers were synthesized by Life Technologies. E. coli transformations were performed with a Gene Pulser following the manufacturer's recommended instructions (Bio-Rad Laboratories). Transformation of $L$. lactis was performed using the procedure of Holo \& Nes (1989).

Construction of a genomic library of L. lactis LM0230. Chromosomal DNA was isolated from stationary phase M17G grown L. lactis LM0230 by the method of Ausubel et al. (1989). DNA was partially digested with Sau3AI and fragments were separated on a $1.0 \%$ agarose gel. Chromosomal fragments between approximately 6.5 and $9.5 \mathrm{~kb}$ were isolated using a GeneCapsule (Geno Technology). Fragments were ligated with alkaline phosphatase treated, BamHI digested pTRKL2. The products of ligation were electroporated into $E$. coli SURE and cells were plated onto LB agar containing Em (LBE). After incubation for $1 \mathrm{~d}$ at $37^{\circ} \mathrm{C}, 2030$ white colonies were picked into LBE broth, grown overnight and $125 \mu \mathrm{l}$ aliquots from each were combined in a centrifuge tube. 
Table 1. Bacterial strains and plasmids

\begin{tabular}{|c|c|c|}
\hline Strain or plasmid & Relevant characteristics* & Source or reference \\
\hline \multicolumn{3}{|l|}{ E. coli } \\
\hline SURE & $\mathrm{F}^{\prime}$ pro $A B \operatorname{lacl}^{q} Z \Delta\left[\mathrm{M} 15 \operatorname{Tn} 10\left(\operatorname{Tet}^{\mathrm{r}}\right)\right]$ & Stratagene \\
\hline DL39 & ilvE12 tyrB507 aspC13 & $\begin{array}{l}\text { LeMaster \& Richards (1988); E. coli } \\
\text { Genetic Stock Center, Yale } \\
\text { University }\end{array}$ \\
\hline \multicolumn{3}{|l|}{ L. lactis } \\
\hline LM0230 & Plasmid free & Efstathiou \& McKay (1976) \\
\hline JLS400 & $\begin{array}{l}\text { LM0230 containing a } 270 \text { bp internal } \\
\text { deletion in aspC }\end{array}$ & This study \\
\hline \multicolumn{3}{|l|}{ Plasmids } \\
\hline pTRKL2 & $\mathrm{Em}^{\mathrm{r}} \operatorname{lac} Z, 6.4 \mathrm{~kb}$ & O’Sullivan \& Klaenhammer (1993) \\
\hline pMOB & $\mathrm{Ap}^{\mathrm{r}}, 1.8 \mathrm{~kb}$ & Gold BioTechnology \\
\hline pG $\mathrm{G}^{+}$host 5 & $\begin{array}{l}\mathrm{Em}^{\mathrm{r}} \text { temperature sensitive } \\
\text { lactococcal integration vector, } \\
5 \cdot 3 \mathrm{~kb}\end{array}$ & Biswas et al. (1993) \\
\hline pJK550 & $\begin{array}{l}\mathrm{Lac}^{+} \operatorname{PrtP}^{+} \text {plasmid from L. lactis } \\
\mathrm{C} 2 \mathrm{O}, 55 \cdot 0 \mathrm{~kb}\end{array}$ & Yu et al. (1996) \\
\hline pSUW414 & AspC $^{+}$pTRKL2 derivative, $15 \cdot 1 \mathrm{~kb}$ & This study \\
\hline pSUW415 & AspC $^{+}$pTRKL2 derivative, $14 \cdot 2 \mathrm{~kb}$ & This study \\
\hline pSUW416 & AspC $^{+}$pTRKL2 derivative, $16 \cdot 1 \mathrm{~kb}$ & This study \\
\hline pSUW417 & AspC $^{+}$pTRKL2 derivative, $13.9 \mathrm{~kb}$ & This study \\
\hline pSUW418 & pTRKL2 derivative, $12 \cdot 0 \mathrm{~kb}$ & This study \\
\hline pSUW419 & $\begin{array}{l}\text { pMOB derivative containing } 2 \cdot 3 \mathrm{~kb} \\
\text { Sall fragment of pSUW } 417\end{array}$ & This study \\
\hline pSUW420 & $\begin{array}{l}\text { AspC }{ }^{+} \text {pTRKL2 derivative; vector- } \\
\text { encoded lacZ promoter located } 5^{\prime} \\
\text { of aspC }\end{array}$ & This study \\
\hline pSUW421 & $\begin{array}{l}\text { AspC }{ }^{+} \text {pTRKL2 derivative, vector- } \\
\text { encoded lacZ promoter located 3' } \\
\text { of aspC }\end{array}$ & This study \\
\hline pSUW422 & pTRKL2 derivative encoding $\triangle a s p C$ & This study \\
\hline pSUW423 & $\mathrm{pG}^{+}$host 5 derivative encoding $\Delta a s p C$ & This study \\
\hline
\end{tabular}

* $\Delta$ aspC, lactococcal aspC containing a $270 \mathrm{bp}$ internal deletion; Tet $^{\mathrm{r}}$, tetracycline resistant.

Plasmid DNA was isolated from the combined cultures by alkaline lysis (Sambrook et al., 1989).

Cloning of aspC by complementation in E. coli DL39. The plasmid pool created above was electroporated into E. coli DL39. Colonies growing on M9 plates lacking Asp were picked into LBE broth and plasmid encoded ATase activities were confirmed by enzyme assays.

DNA sequencing and sequence analysis. DNA sequencing was performed essentially as described by Chen \& Steele (1998), using the Tn1000 kit (Gold BioTechnology) to generate nested sets of transposon insertions in pSUW419. Sequencing reactions were performed using the ABI PRISM Dye Terminator Cycle Sequencing Ready Reaction Kit (Perkin ElmerApplied Biosystems) and a DNA Thermal Cycler 480 (Perkin Elmer-Applied Biosystems). Sequencing reactions were analysed on an ABI 377XL Automated DNA Sequencer at the University of Wisconsin-Madison Biotechnology Center. Additional sequence information was obtained using primer walking to sequence across the SalI site of pSUW417. Sequences were analysed using the GCG sequence analysis package (Genetics Computer Group). Searches for protein sequences similar to the putative AspC sequence were performed using the BLAST network service (Altschul et al., 1997).

Subcloning of the lactococcal aspC. PCR subcloning of the aspC gene was accomplished using the primers 5'-AAAAAAAGATCTTCAATAAAGCGAACCAAG-3' (AspC-up) and 5'-ATATAAAGATCTCTAATTCAAAATCAGCCG-3' (AspC-down), and pSUW417 as template DNA (see Fig. 3). The primers were designed with a 6 bp recognition site for $B g l$ II $\left(5^{\prime}\right.$-AGATCT- $\left.3^{\prime}\right)$ at the $5^{\prime}$ end. PCR was performed using the PCR Elongase Kit of Life Technologies. The cycling conditions were: $94^{\circ} \mathrm{C}$ for $30 \mathrm{~s}, 50^{\circ} \mathrm{C}$ for $30 \mathrm{~s}$ and $68^{\circ} \mathrm{C}$ for $2 \mathrm{~min}$ for 30 cycles. The amplified product was digested with $B g l I I$ and ligated to alkaline phosphatase treated, BglII digested pTRKL2. Ligation products were electroporated into E. coli SURE and transformants were plated onto LBE supplemented with IPTG and X-Gal. White colonies were picked into LBE broth, plasmids were isolated using alkaline lysis and plasmids carrying the amplified product were identified by restriction digests and enzyme assays.

Preparation of cell-free extracts (CFEs). Overnight cultures of 
E. coli $(250 \mathrm{ml})$ were disrupted with glass beads as described by Gao et al. (1997), except CFEs were prepared in $100 \mathrm{mM}$ Bistris, pH 6.5.

ATase enzyme assays. When screening E. coli derivatives for AspC activity, the Aspartate Aminotransferase UV-test kit of Sigma was used. For quantitative assays with each of the 20 common amino acids, the assay contained in 1.4 $\mathrm{ml}$ : CFE ( $12 \mu \mathrm{g}$ protein), $83 \mathrm{mM}$ Bistris ( $\mathrm{pH} 6.8$ ), $6.7 \mathrm{mM}$ amino acid, $54 \mu \mathrm{M}$ pyridoxal-5-phosphate and $6.7 \mathrm{mM}$ 2-oxoglutarate. The reaction temperature was $30^{\circ} \mathrm{C}$. At 5,10 and $15 \mathrm{~min}, 400 \mu \mathrm{l}$ aliquots of the reaction mixture were withdrawn and added to $200 \mu \mathrm{l} 0 \cdot 25 \mathrm{M} \mathrm{HCl}$. Zero minute time points were made by adding the components of the enzyme assay directly into $200 \mu \mathrm{l} 0.25 \mathrm{M} \mathrm{HCl}$. After all time points were taken, samples were centrifuged to remove precipitated protein and the glutamate concentration in each stopped reaction was measured using the colorimetric L-glutamic acid assay kit of Roche Biomolecular. Specific activities were calculated as $\mu \mathrm{mol}$ formazan formed $\min ^{-1}(\mathrm{mg} \text { protein })^{-1}$, using the extinction coefficient of formazan at $492 \mathrm{~nm}$ $\left(19.9 \mathrm{mmol}^{-1} \mathrm{~cm}^{-1}\right)$.

Protein concentrations were determined using the Micro Protein Determination kit of Sigma and BSA as the protein standard.

Construction of $\mathbf{L}$. lactis JLS400. An internal deletion was introduced into aspC as follows. The lactococcal aspC was amplified from pSUW421 using the primers AspC-up and AspC-down. After purification of the amplified product using a QIAquick PCR purification column (Qiagen), the DNA fragment was digested with $B g l \mathrm{II}$, ethanol precipitated and ligated at low concentrations [about $1-5$ ng DNA ( $\mu$ l ligation reaction $)^{-1}$ ] to favour intramolecular ligation. A $1 \mu$ l aliquot of the ligation reaction was used as template DNA in a PCR reaction containing the primers Del1 (5'-P-AAATCCGACCGCTGTTGCTC-3') and Del2 (5'-P-ATTCCTGTTGGATTTGAAGGC-3') (see Fig. 3). The same PCR cycling conditions as described above for the primers AspC-up and AspC-down were used. The resulting product was purified using a QIAquick column, and was intramolecularly ligated. A third round of PCR and column purification was performed as described above using the primers AspC-up and AspC-down. The resulting DNA fragment was digested with BglII and ligated into similarly digested pTRKL2. The ligation mixture was transformed into E. coli SURE. Restriction analysis was used to identify plasmids carrying the deleted gene $(\Delta a s p C)$ and sequence analysis using primer $5^{\prime}$-TTTGCCCTCTACGCTTAC-3' was used to screen for plasmids containing the desired $270 \mathrm{bp}$ internal deletion in aspC. A plasmid that contained the appropriate deletion was designated pSUW422. The $\Delta a s p C$ fragment was liberated from pSUW422 with $B g l I I$ and ligated into similarly digested $\mathrm{pG}^{+}$host5 (Biswas et al., 1993), forming pSUW423.

The $\Delta a s p C$ fragment was introduced into the chromosome of L. lactis LM0230 using pSUW423 and the double-crossover homologous integration method of Biswas et al. (1993). Strains containing the $270 \mathrm{bp}$ deletion in aspC were screened for by PCR using the primers AspC-up and AspC-down.

Growth studies in defined medium and skimmed milk. $L$. lactis strains were grown from a $1 \%$ inoculum in M17-L containing Em until early stationary phase $(9-11 \mathrm{~h})$. A $1 \mathrm{ml}$ aliquot of cells was centrifuged, washed twice with $0.85 \%$ $\mathrm{NaCl}$ and resuspended in $1 \mathrm{ml} 0.85 \% \mathrm{NaCl}$. Cells were inoculated into $30 \mathrm{ml} \mathrm{DM}$ containing Em or $100 \mathrm{ml}$ steamed milk containing Em to an initial $\mathrm{OD}_{600}$ of 0.01 or 0.001 , respectively. Cells were incubated at $30{ }^{\circ} \mathrm{C}$ and $\mathrm{OD}_{600}$ readings were recorded from DM or clarified milk as described previously (Chen \& Steele, 1998). If necessary, cell suspensions after milk clarification or from DM cultures were diluted in $100 \mathrm{mM}$ Bistris, $\mathrm{pH} 6 \cdot 5$, or water respectively, to obtain an $\mathrm{OD}_{600}$ between $0 \cdot 03$ and $0 \cdot 30$. These values were determined to be within the linear range for cell density readings. Readings for $\mathrm{pH}$ were determined using an Orion Research model $410 \mathrm{~A}$ $\mathrm{pH}$ meter equipped with a Mettler Toledo Ingold Electrode (Nelson-Jameson). Values for $\mu_{\max }$ are reported as the mean of 4-6 growth experiments \pm SD.

\section{RESULTS}

\section{Cloning of L. lactis genes which complement the Asp auxotrophy of $E$. coli DL39}

The L. lactis LM0230 genomic library was electroporated into E. coli DL39. This strain is unable to grow in the absence of Asp due to mutations in aspC and tyrB (LeMaster \& Richards, 1988). A total of 33 DL39 derivatives containing chromosomal inserts were isolated on M9 plates lacking Asp. The EcoRI digests of the plasmids from the 33 colonies were compared and five patterns were observed (Fig. 1). Enzyme assays indicated four of the five plasmids (pSUW414, pSUW415, pSUW416, pSUW417) encode for aspartate ATase activity. No aspartate ATase activity was detected in CFEs of E. coli DL39(pSUW418).

\section{Plasmids pSUW414, pSUW415, pSUW416 and pSUW417 all encode the $L$. lactis LM0230 aspC}

The construct pSUW417 was chosen for further analysis. A restriction map of the $7 \cdot 5 \mathrm{~kb}$ chromosomal insert was generated (Fig. 2), and deletion and subcloning analyses were used to further localize the gene encoding aspartate

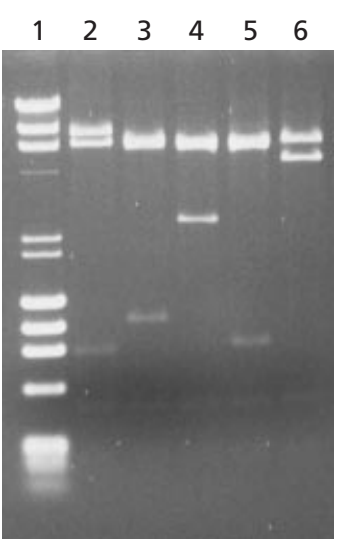

Fig. 1. EcoRI restriction endonuclease digestion of five plasmids derived from the Lactococcus lactis LM0230 genomic library that complemented the Asp auxotrophy of E. coli DL39. DNA fragments were separated on a $1.2 \%$ agarose gel after digestion. Lanes: $1, \lambda \times$ HindIII and $\phi \times 174 \times$ HaellI molecular mass size standards; 2 , pSUW414; 3 , pSUW415; 4, pSUW416; 5 , pSUW417; 6, pSUW418. 


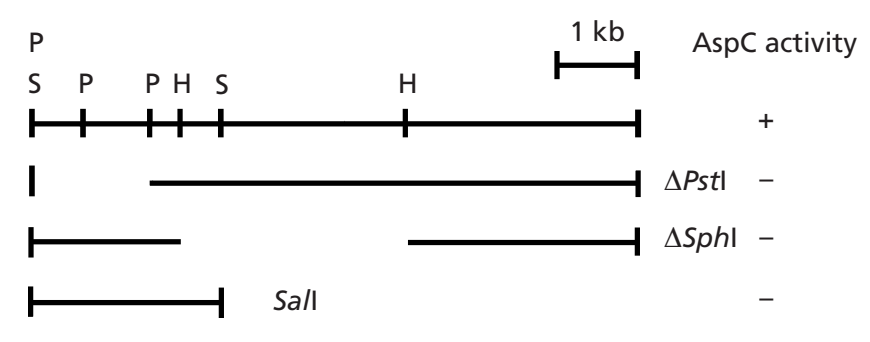

Fig. 2. Restriction endonuclease map of the pSUW417 insert and localization of the Lactococcus lactis LM0230 aspC gene. The lines marked $\Delta P s t l$ and $\Delta S p h l$ indicate the fragments deleted in those constructs. The line marked Sall indicates the fragment that was subcloned. The AspC phenotype of the constructs is indicated to the right of the lines. P, Pstl; S, Sall; H, Sphl.

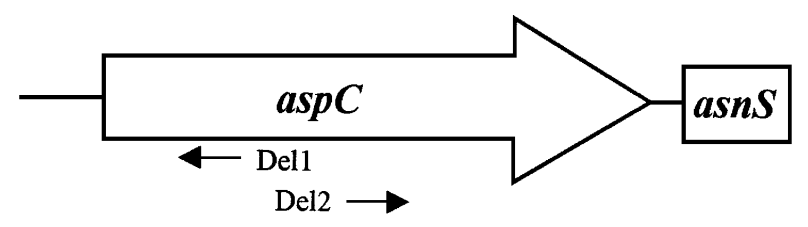

AspC-up

$\longleftarrow$ AspC-down

Fig. 3. Schematic representation of L. lactis LM0230 aspC and the partial asnS sequenced from pSUW417. The large arrow designates the putative direction of transcription of aspC, as deduced by the nucleotide sequence. Based upon the nucleotide sequence, transcription of asns is in the same direction as aspC. The arrows marked Del1 and Del2 indicate the approximate location and direction of the primers used to introduce a deletion into aspC. The arrows marked AspC-up and AspC-down indicate the approximate location and direction of the primers used to subclone aspC.

ATase activity. Deletion of the $S p h \mathrm{I}$ or PstI fragments internal to the chromosomal insert both eliminated AspC activity. Additionally, no AspC activity was detected when the $2.3 \mathrm{~kb}$ Sal fragment from the insert was subcloned in pTRKL2 and transformed into E. coli DL39. These results suggested the insert-derived SalI restriction site was located within aspC or a region necessary for aspC expression. Therefore, the $2.3 \mathrm{~kb}$ Sal fragment from pSUW417 was subcloned into pMOB forming pSUW419 and this insert was partially sequenced. Comparison of translated sequences from ORFs identified on this fragment with AspC sequences in GenBank suggested the C-terminal 264 aa of the lactococcal AspC were encoded on pSUW419. Therefore, primer walking was used to sequence the remaining part of aspC using pSUW417 as template DNA.

Double-stranded sequence data were obtained for a $1.89 \mathrm{~kb}$ region of pSUW417. An ORF of $1179 \mathrm{bp}$ which could encode a 393 aa, $43 \cdot 2 \mathrm{kDa}$ protein was identified. Putative -10 (TAAATA) and -35 (TACAAA) promoter sequences and a putative ribosome-binding site (AGGAAA) were identified $5^{\prime}$ of the ORF. No rhoindependent transcriptional terminator was identified 3' of this ORF by the Terminator program of GCG. BLAST (Altschul et al., 1997) searches found the deduced amino acid sequence for this ORF has identity to AspCs and putative AspCs from other organisms. The highest identities were found with sequences from Bacillus stearothermophilus (Bartsch et al., 1996), Bacillus subtilis (Sorokin et al., 1996), Bacillus sp. strain YM-2 (Sung et al., 1991), Streptomyces coelicolor (Redenbach et al., 1996) and Streptomyces virginiae (Katayama et al., 1995) (52, 52, 51, 45 and $44 \%$ identity to the L. lactis ORF over $>382$ aa residues, respectively). Additionally, amino acids $236-249$ of the $L$. lactis sequence conformed to the PROSITE pattern PS00105 (Hofmann et al., 1999) defining an ATase class I pyridoxal phosphate attachment site. Using this defined motif, $\mathrm{Lys}_{239}$ was identified as the attachment site for pyridoxal phosphate, an essential cofactor for ATase activity.

Downstream of aspC, a partial ORF was identified (Fig. 3). A BLAST search of the deduced amino acid sequence

Table 2. Growth characteristics of L. lactis LM0230 and JLS400 derivatives in minimal media, defined media and skimmed milk

Values for $\mu_{\max }$ are reported as the mean of either 4 (for DM) or 5-6 (for skimmed milk) independent experiments \pm SD. ND, No growth detected. For growth in minimal media, cells were inoculated to an initial $\mathrm{OD}_{600}$ of $0 \cdot 1:+, \mathrm{OD}_{600}>0 \cdot 6$ after $2 \mathrm{~d}$ growth at $30{ }^{\circ} \mathrm{C} ;-, \mathrm{OD}_{600}<0 \cdot 2$ after $2 \mathrm{~d}$ growth at $30^{\circ} \mathrm{C}$.

\begin{tabular}{|lcccc|}
\hline & $\begin{array}{c}\text { LM0230 } \\
\text { (pJK550, } \\
\text { pTRKL2) }\end{array}$ & $\begin{array}{c}\text { LM0230 } \\
\text { (pJK550, } \\
\text { pSUW421) }\end{array}$ & $\begin{array}{c}\text { JLS400 } \\
\text { (pJK550, } \\
\text { pTRKL2) }\end{array}$ & $\begin{array}{c}\text { JLS400 } \\
\text { (pJK550, } \\
\text { pSUW421) }\end{array}$ \\
\hline$\mu_{\max }$ in DM & $0 \cdot 62 \pm 0 \cdot 01$ & $0 \cdot 60 \pm 0 \cdot 01$ & $0 \cdot 59 \pm 0 \cdot 01$ & $0 \cdot 60 \pm 0.01$ \\
$\mu_{\max }$ in skimmed milk & $0 \cdot 40 \pm 0 \cdot 02$ & $0 \cdot 39 \pm 0 \cdot 02$ & ND & $0 \cdot 38 \pm 0 \cdot 02$ \\
Growth in MS15 & + & + & - & + \\
Growth in MS15 + Asp* & + & + & - & + \\
Growth in MS15 + Asn" & + & + & + & + \\
\hline
\end{tabular}

* MS15 minimal media supplemented with $0 \cdot 42 \mathrm{~g} \mathrm{Asp}^{-1}$ or 0.125 $\mathrm{g} \mathrm{Asn} \mathrm{l}^{-1}$. 
indicated this ORF might encode the N-terminal 75 residues of an asparaginyl-tRNA synthetase.

To confirm the identified ORF encodes the AspC activity detected in E. coli DL39(pSUW417), the ORF was amplified by PCR using primers Asp-up and Asp-down (Fig. 3). This fragment was cloned into pTRKL2 in both orientations with respect to the vector lacZ promoter, forming pSUW420 and pSUW421. AspC activity was detected in CFEs of both E. coli DL39(pSUW420) and DL39(pSUW421).

PCR reactions using the primers Asp-up and Asp-down successfully amplified a $1.5 \mathrm{~kb}$ fragment from the plasmid templates pSUW414, pSUW415 and pSUW416. Partial sequencing of these PCR products indicated all three of these plasmids encode aspC. No product was amplified when pSUW418 was used as template DNA.

\section{The L. lactis LM0230 aspartate ATase has activity with Asp and no detectable activity with any other amino acids}

The specific activity of AspC from CFEs of E. coli DL39(pSUW420) using Asp and 2-oxoglutarate as amino donor and amino acceptor, respectively, was calculated to be $1.07 \pm 0.06 \mu \mathrm{mol}$ formazan formed $\min ^{-1}$ (mg protein $)^{-1}$. This value was determined from duplicate assays performed on two independent cultures of E. coli DL39 (pSUW420). For all of the other common amino acids except for Cys, activities were below the quantifiable limit $\left[0.06 \mu \mathrm{mol} \mathrm{min}^{-1}(\mathrm{mg} \text { protein })^{-1}\right]$. Assays using Cys as the substrate were inconclusive, as reducing agents interfere with the reaction catalysed by the L-glutamic acid assay kit.

\section{A L. lactis $\Delta a s p C$ derivative requires Asp or Asn supplementation to grow in synthetic media or milk}

A L. lactis LM0230 derivative containing a $270 \mathrm{bp}$ internal deletion in $a s p C$ was constructed and designated JLS400. LM0230 and JLS400 were both transformed with pJK550, a plasmid carrying the genes for lactose utilization and PrtP of L. lactis C2O (Yu et al., 1996), which are essential for growth to high cell densities in milk. Additionally, the pJK550-containing strains were transformed with either pTRKL2 or pSUW421.

In DM, all four strains [LM0230(pJK550, pTRKL2), LM0230(pJK550, pSUW421), JLS400(pJK550, pTRKL2) and JLS400(pJK550, pSUW421)] entered exponential growth within $4 \cdot 5-5 \cdot 0 \mathrm{~h}$ after inoculation, produced acid at similar rates and reached a final $\mathrm{OD}_{600}$ of $2 \cdot 2-2 \cdot 4$ (data not shown). Additionally, similar $\mu_{\max }$ values were calculated for all four strains (Table 2). Growth of LM0230(pJK550, pTRKL2), LM0230(pJK550, pSUW421) and JLS400(pJK550, pSUW421) occurred in MS15 minimal media (Table 2). JLS400(pJK550, pTRKL2) grew in MS15 supplemented with Asn, but did not grow in MS15 or MS15 supplemented with Asp.
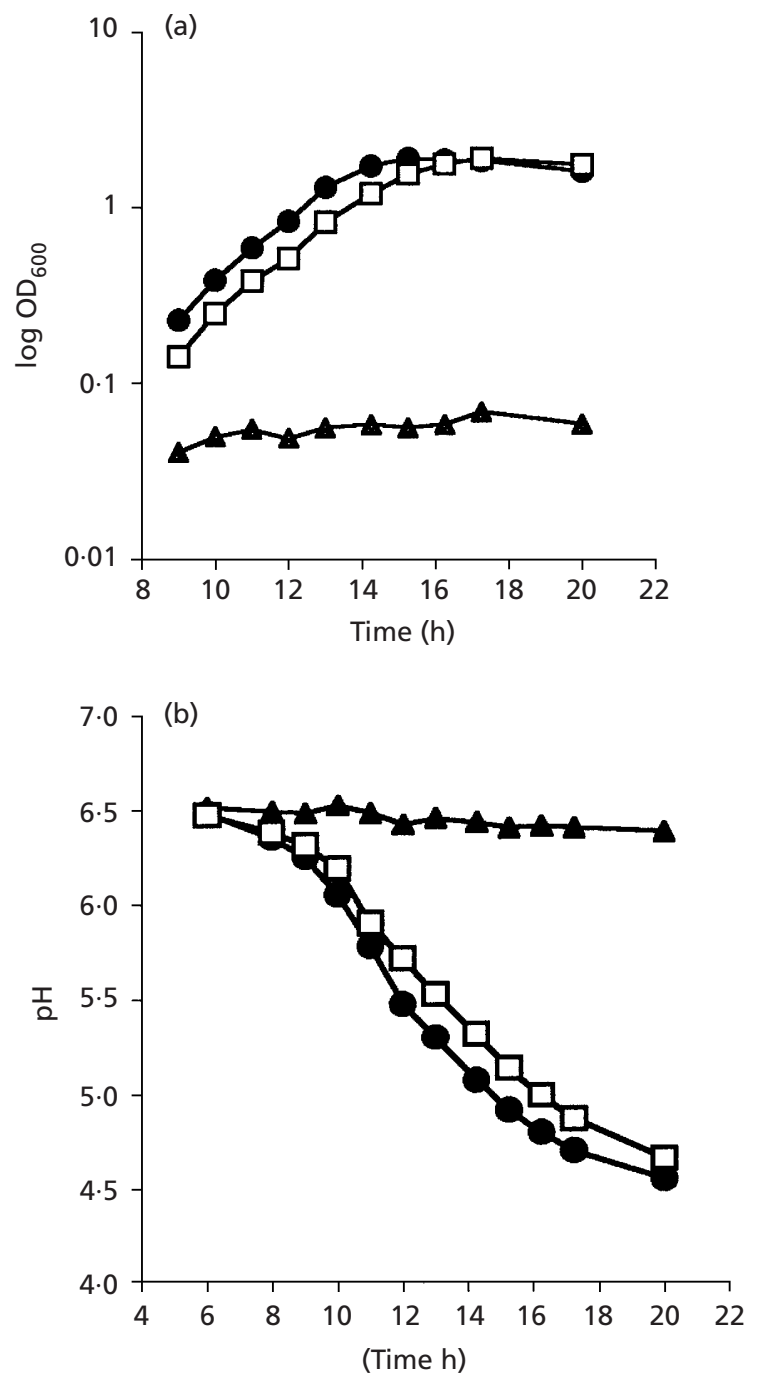

Fig. 4. Milk growth (a) and $\mathrm{pH}(\mathrm{b})$ curves of Lactococcus lactis LM0230(pJK550, pTRKL2) (AspC ${ }^{+}, 0$ ), JLS400(pJK550, pTRKL2) $\left(\mathrm{AspC}^{-} ; \boldsymbol{A}\right)$ and JLS400(pJK550, pSUW421) (AspC $\left.{ }^{+} ; \square\right)$. The plot for LM0230(pJK550, pSUW421) is not shown as it overlapped that of LM0230(pJK550, pTRKL2). Values shown are the means of two samples taken per time point. The graphs are representative data from 5-6 independent growth and $\mathrm{pH}$ curves.

LM0230(pJK550, pTRKL2) and LM0230(pJK550, pSUW421) grew similarly in skimmed milk (Fig. 4a and Table 2). However, JLS400(pJK550, pTRKL2) did not grow or produce acid at a detectable rate in milk (Fig. 4). The $\mu_{\max }$ for JLS400(pJK550, pSUW421) was not statistically different from LM0230(pJK550, pTRKL2) or LM0230(pJK550, pSUW421), although a lag period approximately $1 \mathrm{~h}$ longer was observed for this strain compared to the latter two. Three strains of LM0230(pJK550, pSUW421) which were independently constructed all displayed the same lag period when inoculated into milk, suggesting the lag period was not the result of unintended mutations created during strain construction. 


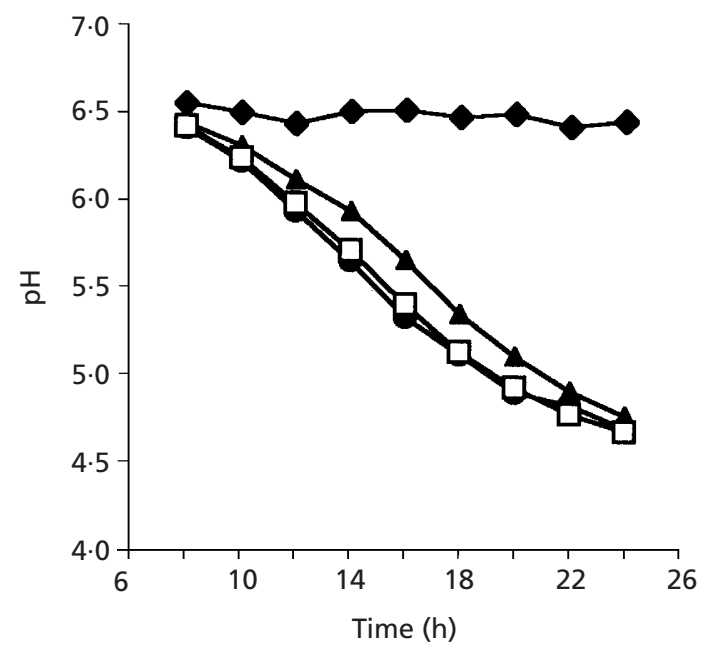

Fig. 5. Acidification rates of Lactococcus lactis LM0230(pJK550, pTRKL2) (AspC $\left.{ }^{+} ; 0\right)$ ), JLS400(pJK550, pTRKL2) (AspC $\left.{ }^{-} ; \mathbf{\Delta}\right)$, JLS400(pJK550, pSUW421) (AspC $\left.{ }^{+} ; \square\right)$ and a blank ( $\bullet$ ) in milk supplemented with $0.42 \mathrm{~g} \mathrm{Asp} \mathrm{I}^{-1}$. The plots are representative data from two independent growth experiments. The plot for LM0230(pJK550, pSUW421) is not shown, as it overlapped that of LM0230(pJK550, pTRKL2).

Supplementation of milk with Asp or Asn restored the ability of JLS400(pJK550, pTRKL2) to acidify milk; however, the acidification rate in Asp-supplemented milk was slightly lower than that for LM0230(pJK550, pTRKL2), LM0230(pJK550, pSUW421) or JLS400(pJK550, pSUW421) (Fig. 5). Acidification rates of JLS400(pJK550, pSUW421) in milk supplemented with Asp (Fig. 5) or Asn (data not shown) were indistinguishable from those of LM0230(pJK550, pTRKL2) and LM0230(pJK550, pSUW421).

\section{DISCUSSION}

To facilitate the cloning of aspC, as well as other genes from L. lactis LM0230, a genomic library consisting of 2030 plasmid derivatives was constructed in E. coli. Using the formula of Clarke \& Carbon (1976), a genomic size of $2.6 \times 10^{3} \mathrm{kbp}$ for L. lactis LM0230 (Davidson et al., 1996), and a mean chromosomal insert size in pTRKL2 of $7.9 \mathrm{~kb}$ (data not shown), we can conclude that the probability of all clonable genes being represented within this library is greater than $99 \%$. This conclusion is supported by the fact that the lactococcal aspC was isolated on four different plasmids. One plasmid, designated pSUW418, which did not encode AspC activity, also complemented the Asp auxotrophy of E. coli DL39. Preliminary sequence data suggests this plasmid may carry a gene or genes involved in amino acid transport (Dudley \& Steele, unpublished data).

AspCs are members of family I of the ATase superfamily (Jensen \& Gu, 1996). Dendrograms aligning the sequences of ATases involved in the interconversion of aspartate and oxaloacetate reveal two distinct homology groups defined by Jensen $\&$ Gu (1996) as subfamilies I $\alpha$ and $\mathrm{I} \gamma$ (also defined as subfamilies Ia and Ib respectively by Okamoto et al., 1996). These two families may differ slightly in their catalytic mechanism (Nakai et al., 1999). Subfamily I $\alpha$ includes AspC from E. coli, and eukaryote cytosolic and mitochondrial AspCs. Subfamily I $\gamma$ includes the rest of the known eubacterial and archaeal AspCs. Based upon the results of BLAST searches, the lactococcal AspC is most similar to sequences within the I $\gamma$ group. The conservation of active site residues suggested to exist only within the I $\gamma$ subfamily (Nakai et al., 1999), such as Lys ${ }_{109}\left(\right.$ Lys $_{102}$ in L. lactis) and $\mathrm{Thr}_{36}{ }^{-}$ $\mathrm{Ala}_{37}-\mathrm{Gly}_{38}\left(\mathrm{Thr}_{37}-\mathrm{Leu}_{38}-\mathrm{Gly}_{39}\right.$ in L. lactis), supports this classification.

No rho-independent terminator was identified between the $3^{\prime}$ end of $a s p C$ and the start of the ORF for a putative asparaginyl-tRNA synthetase (asnS). The genes for aspC and asnS in B. subtilis are also adjacent on the chromosome (Sorokin et al., 1996), although a transcriptional terminator with $\Delta G=-54.4 \mathrm{~kJ} \mathrm{~mol}^{-1}$ (Tinoco et al., 1973) is found immediately $3^{\prime}$ of the aspC ORF. However, it is unknown whether the lactococcal aspC is monocistronic or cotranscribed with asnS. The construct pSUW421 was capable of complementing the chromosomal aspC deletion in JLS400, suggesting cotranscription of aspC with the downstream asnS is not essential for expression of aspC in L. lactis. Further studies on the expression of $a s p C$ are needed to determine the mode of transcription of this gene.

Bacterial cells typically contain a number of ATases with overlapping substrate specificity (Jensen \& Calhoun, 1981). For example, in E. coli both AspC and $\mathrm{TyrB}$, an ATase that is preferentially active on aromatic amino acids, catalyse the transamination of oxaloacetate to Asp. However, growth studies in MS15 and milk suggest no other L. lactis enzyme can transaminate oxaloacetate in vivo efficiently enough to support growth under Asp-limiting conditions. This is consistent with the substrate specificity of the lactococcal aromatic (Gao \& Steele, 1998; Yvon et al., 1997) and branchedchain (Atiles et al., 2000; Yvon et al., 2000) ATases, which lack detectable activity with Asp. Asp also appears to be the only amino acid substrate for AspC. Many other subfamily I $\gamma$ AspC homologues also have relative activities with Asp that are at least 100-fold higher than the activities with other amino acids (Marino et al., 1988; Sung et al., 1990; Xing \& Whitman, 1992; Okamoto et al., 1996). However, the inability to detect activity of the lactococcal AspC with amino acids other than Asp may also have been due to the lack of sensitivity of the assay used, which was approximately $6 \%$ relative activity to that observed with Asp.

In a previous study a lactococcal strain was isolated after acriflavine mutagenesis which was unable to acidify $11 \%$ reconstituted skimmed milk to a $\mathrm{pH}$ less than approximately $5 \cdot 0$ in $6 \mathrm{~h}$ unless supplemented with Asp (Wang et al., 1998). This strain, designated KB4, produces decreased levels of the protein pyruvate carboxylase (Wang et al., 2000), has approximately $5 \%$ the pyruvate carboxylase activity of the wild-type strain 
(Wang et al., 1998) and lacks a $12 \mathrm{MDa}$ plasmid present in the parent strain. The exact molecular basis of the mutation or mutations in KB4 has not been reported. As pyruvate carboxylase catalyses the formation of oxaloacetate, the biosynthetic precursor to Asp, this data suggested the growth defect was due to a decreased level of Asp production by KB4. This current study used homologous recombination to construct isogenic strains and demonstrate that a mutation in the L. lactis Asp biosynthetic pathway is sufficient to eliminate this strain's ability to grow in milk. During six growth curve replicates, the strain which lacked both the wild-type chromosomal and plasmid copy of aspC never acidified milk to more than $0 \cdot 20 \mathrm{pH}$ units below that of the blank and did not grow at a detectable rate. As oligopeptides liberated from caseins by the lactococcal PrtP serve as the major nitrogen source for L. lactis in milk (Juillard et al., 1995a), and L. lactis can apparently transport and hydrolyse at least one Asp-containing peptide from $\beta$-casein (Kunji et al., 1998), the inability of JLS400(pJK550, pTRKL2) to rapidly grow in or acidify milk suggests $L$. lactis is unable to liberate an adequate level of Asp or Asn from milk caseins to support optimal growth. As Asp is the biosynthetic precursor for Asn, threonine, lysine and methionine, as well as pyrimidine and purine nucleotides, Asp biosynthesis may also be essential for supplying the cell with sufficient levels of these biological compounds. It has previously been shown that L. lactis purine auxotrophs are unable to grow in milk (Dickely et al., 1995); however, the necessity of threonine, lysine or pyrimidine biosynthesis is unknown. Asp is probably not diverted towards methionine biosynthesis in dairy lactococci, as these organisms are typically auxotrophic for methionine (Chopin, 1993). Studies using milk supplemented with amino acids and nucleotides will be necessary to determine whether the growth defect of JLS400 (pJK550, pTRKL2) is the direct result of the Asp auxotrophy, and/or is an indirect effect on other biosynthetic pathways.

One surprising result from the growth studies was that JLS400(pJK550, pTRKL2) failed to grow in MS15 media supplemented with Asp, but did grow when supplemented with Asn. The most likely explanation is that $L$. lactis LM0230 can convert Asn to Asp via an asparagine synthetase or related enzyme, and transport of free Asn is energetically more favourable than Asp transport. This is supported by previous studies which have shown that lactococci do not readily transport free Asp (Hillier et al., 1978) and that the affinity constant of the Asp transporter is approximately 80 -fold higher than the affinity constant of the Asn transporter, for their respective substrates $(250 \mu \mathrm{M}$ vs $3 \mu \mathrm{M}$, respectively) (Konings et al., 1989). This hypothesis is additionally supported by the fact that JLS400(pJK550, pTRKL2) acidifies Asp-supplemented milk slower than JLS400(pJK550, pSUW421) (Fig. 5), while these two strains acidify Asn-supplemented milk at the same rate (data not shown).

Experiments to clone other ATase genes from L. lactis are ongoing. Construction of single and multiple ATase mutants will be used to further study the physiological role of these enzymes during growth in milk as well as their potential role in the generation of flavour precursors in fermented products.

\section{ACKNOWLEDGEMENTS}

This project was supported by the Wisconsin Center for Dairy Research through funding from Dairy Management, Inc., and the College of Agriculture and Life Science at the University of Wisconsin-Madison.

We thank Myrta Atiles and Cedric Mendiola for assistance in construction of the L. lactis LM0230 genomic library.

\section{REFERENCES}

Atiles, M. W., Dudley, E. G. \& Steele, J. L. (2000). Gene cloning, sequencing, and inactivation of the branched-chain aminotransferase of Lactococcus lactis LM0230. Appl Environ Microbiol 66, 2325-2329.

Altschul, S. F., Madden, T. L., Schäffer, A. A., Zhang, J., Zhang, Z., Miller, W. \& Lipman, D. J. (1997). Gapped BLAST and PSI-BLAST: a new generation of protein database search programs. Nucleic Acids Res 25, 3389-3402.

Ausubel, F. M., Brent, R., Kingston, R. E., More, D. D., Seidman, J. G., Smith, J. A. \& Struhl, K. (1989). Current Protocols in Molecular Biology, vol. 1. New York: Green Publishing Associates and Wiley Interscience.

Bartsch, K., Schneider, R. \& Schulz, A. (1996). Stereospecific production of the herbicide phosphinothricin (glufosinate): purification of aspartate transaminase from Bacillus stearothermophilus, cloning of the corresponding gene, aspC, and application in a coupled transaminase process. Appl Environ Microbiol 62, 3794-3799.

Biswas, I., Gruss, A., Ehrlich, S. D. \& Maguin, E. (1993). Highefficiency gene inactivation and replacement system for grampositive bacteria. J Bacteriol 175, 3628-3635.

Bruinenberg, P. G., Vos, P. \& de Vos, W. M. (1992). Proteinase overproduction in Lactococcus lactis strains: regulation and effect on growth and acidification in milk. Appl Environ Microbiol 58, 78-84.

Chen, Y. \& Steele, J. L. (1998). Genetic characterization and physiological role of endopeptidase $\mathrm{O}$ from Lactobacillus helveticus CNRZ32. Appl Environ Microbiol 64, 3411-3415.

Chopin, A. (1993). Organization and regulation of genes for amino acid biosynthesis in lactic acid bacteria. FEMS Microbiol Rev 12, 21-38.

Christensen, J. E., Dudley, E. G., Pederson, J. A. \& Steele, J. L. (1999). Peptidases and amino acid catabolism in lactic acid bacteria. Antonie Leeuwenhoek 76, 217-246.

Clarke, L. \& Carbon, J. (1976). A colony bank containing synthetic ColE1 hybrid plasmids representative of the entire E. coli genome. Cell 9, 91-99.

Cocaign-Bousquet, M., Garrigues, C., Novak, L., Lindley, N. D. \& Loubiere, P. (1995). Rational development of a simple synthetic medium for sustained growth of Lactococcus lactis. J Appl Bacteriol 79, 108-116.

Davidson, B. E., Kordias, N., Dobos, M. \& Hillier, A. J. (1996). Genomic organization of lactic acid bacteria. Antonie Leeuwenhoek 70, 161-183.

Dickely, F., Nilsson, D., Hansen, E. B. \& Johansen, E. (1995). Isolation of Lactococcus lactis nonsense suppressors and con- 
struction of a food-grade cloning vector. Mol Microbiol 15, 839-847.

Efstathiou, J. D. \& McKay, L. L. (1976). Inorganic salts resistance associated with a lactose-fermenting plasmid in Streptococcus lactis. J Bacteriol 130, 257-265.

Foucaud, C., Kunji, E. R., Hagting, A., Richard, J., Konings, W. N., Desmazeaud, M. \& Poolman, B. (1995). Specificity of peptide transport systems in Lactococcus lactis: evidence for a third system which transports hydrophobic di- and tripeptides. $J$ Bacteriol 177, 4652-4657.

Gao, S. \& Steele, J. L. (1998). Purification and characterization of oligomeric species of an aromatic amino acid aminotransferase from Lactococcus lactis subsp. lactis S3. J Food Biochem 22, 197-211.

Gao, S., Oh, D. H., Broadbent, J. R., Johnson, M. E., Weimer, B. C. \& Steele, J. L. (1997). Aromatic amino acid catabolism by lactococci. Lait 77, 371-381.

Gao, S., Mooberry, E. S. \& Steele, J. L. (1998). Use of ${ }^{13} \mathrm{C}$ nuclear magnetic resonance and gas chromatography to examine methionine catabolism by lactococci. Appl Environ Microbiol 64, $4670-4675$.

Gerhardt, P., Murray, R. G. E., Woods, W. A. \& Krieg, N. R. (1994). Methods for General and Molecular Bacteriology. Washington, DC: American Society for Microbiology.

Hagting, A., Kunji, E. R., Leenhouts, K. J., Poolman, B. \& Konings, W. N. (1994). The di- and tripeptide transport protein of Lactococcus lactis: a new type of bacterial peptide transporter. $J$ Biol Chem 269, 11391-11399.

Helinck, S., Richard, J. \& Juillard, V. (1997). The effects of adding lactococcal proteinase on the growth rate of Lactococcus lactis in milk depend on the type of enzyme. Appl Environ Microbiol 63, 2124-2130.

Hillier, A. J., Rice, G. H. \& Jago, G. R. (1978). Metabolism of $\left[{ }^{14} \mathrm{C}\right]$ bicarbonate by Streptococcus lactis: the synthesis, uptake and excretion of aspartate by resting cells. J Dairy Res 45, 241-246.

Hofmann, K., Bucher, P., Falquet, L. \& Bairoch, A. (1999). The PROSITE database, its status in 1999. Nucleic Acids Res 27, 215-219.

Holo, H. \& Nes, I. F. (1989). High-frequency transformation by electroporation of Lactococcus lactis subsp. cremoris grown with glycine in osmotically stabilized media. Appl Environ Microbiol 55, 3119-3123.

Jensen, R. A. \& Calhoun, D. H. (1981). Intracellular roles of microbial aminotransferases: overlap enzymes across different biochemical pathways. Crit Rev Microbiol 8, 229-266.

Jensen, R. A. \& Gu, W. (1996). Evolutionary recruitment of biochemically specialized subdivisions of family I within the protein superfamily of aminotransferases. J Bacteriol 178, 21612171.

Juillard, V., Le Bars, D., Dunji, E. R. S., Konings, W. N., Gripon, J.-C. \& Richard, J. (1995a). Oligopeptides are the main source of nitrogen for Lactococcus lactis during growth in milk. Appl Environ Microbiol 61, 3024-3030.

Juillard, V., Laan, H., Kunji, E. R., Jeronimus-Stratingh, C. M., Bruins, A. P. \& Konings, W. N. (1995b). The extracellular $\mathrm{P}_{\mathrm{I}}$-type proteinase of Lactococcus lactis hydrolyzes beta-casein into more than one hundred different oligopeptides. J Bacteriol 177, 3472-3478.

Katayama, M., Sakai, Y., Okamoto, S., Ihara, F., Nihira, T. \& Yamada, Y. (1996). Gene organization in the ada-rplL region of Streptomyces virginiae. Gene 171, 135-136.
Konings, W. N., Poolman, B. \& Driessen, A. J. M. (1989). Bioenergetics and solute transport in lactococci. Crit Rev Microbiol 16, 419-476.

Kunji, E. R. S., Fang, G., Jeronimus-Stratingh, C. M., Bruins, A. P., Poolman, B. \& Konings, W. N. (1998). Reconstruction of the proteolytic pathway for use of $\beta$-casein by Lactococcus lactis. Mol Microbiol 27, 1107-1118.

LeMaster, D. M. \& Richards, F. M. (1988). NMR sequential assignment of Escherichia coli thioredoxin utilizing random fractional deuteriation. Biochemistry 27, 142-150.

McKay, L. L., Cords, B. R. \& Baldwin, K. A. (1973). Transduction of lactose metabolism in Streptococcus lactis C2. J Bacteriol 115, 810-815.

Marino, G., Nitti, G., Arnone, M. I., Sannia, G., Gambacorta, A. \& De Rosa, M. (1988). Purification and characterization of aspartate aminotransferase from the thermoacidophilic archaebacterium Sulfolobus solfataricus. J Biol Chem 263, 12305-12309.

Nakai, T., Okada, K., Akutsu, S., Miyahara, I., Kawaguchi, S., Kato, R., Kuramitsu, S. \& Hirotsu, K. (1999). Structure of Thermus thermophilus HB8 aspartate aminotransferase and its complex with maleate. Biochemistry 38, 2413-2424.

Okamoto, A., Kato, R., Masui, R., Yamagishi, A., Oshima, T. \& Kuramitsu, S. (1996). An aspartate aminotransferase from an extremely thermophilic bacterium, Thermus thermophilus HB8. J Biochem 119, 135-144.

O'Sullivan, D. J. \& Klaenhammer, T. R. (1993). High- and lowcopy-number Lactococcus shuttle cloning vectors with features for clone screening. Gene 137, 227-231.

Poolman, B. (1993). Energy transduction in lactic acid bacteria. FEMS Microbiol Rev 12, 125-148.

Redenbach, M., Kieser, H. M., Denapaite, D., Eichner, A., Cullum, J., Kinashi, H. \& Hopwood, D. A. (1996). A set of ordered cosmids and a detailed genetic and physical map for the $8 \mathrm{Mb}$ Streptomyces coelicolor A3(2) chromosome. Mol Microbiol 21, 77-96.

Sambrook, J., Fritsch, E. F. \& Maniatis, T. (1989). Molecular Cloning: a Laboratory Manual, 2nd edn. Cold Spring Harbor, NY : Cold Spring Harbor Laboratory.

Sorokin, A., Azevedo, V., Zumstein, E., Galleron, N., Ehrlich, S. D. \& Serror, P. (1996). Sequence analysis of the Bacillus subtilis chromosome region between the ser $A$ and $k d g$ loci cloned in a yeast artificial chromosome. Microbiology 142, 2005-2016.

Sung, M.-H., Tanizawa, K., Tanaka, H., Kuramitsu, S., Kagamiyama, H. \& Soda, K. (1990). Purification and characterization of thermostable aspartate aminotransferase from a thermophilic Bacillus species. J Bacteriol 172, 1345-1351.

Sung, M.-H., Tanizawa, K., Tanaka, H., Kuramitsu, S., Kagamiyama, H., Hirotsu, K., Okamoto, A., Higuchi, T. \& Soda, K. (1991). Thermostable aspartate aminotransferase from a thermophilic Bacillus species : gene cloning, sequence determination, and preliminary X-ray characterization. J Biol Chem 266, 2567-2572. Swaisgood, H. E. (1985). Characteristics of edible fluids of animal origin: milk. In Food Chemistry, pp. 791-827. Edited by O. R. Fennema. New York: Marcel Dekker.

Terzaghi, B. E. \& Sandine, W. E. (1975). Improved medium for lactic streptococci and their bacteriophages. Appl Microbiol 29, 807-813.

Tinoco, I., Borer, P. N., Dengler, B., Levine, M. D., Uhlenbeck, O. C., Crothers, D. M. \& Gralla, J. (1973). Improved estimation of secondary structure in ribonucleic acids. Nat New Biol 246, 40-41.

Tynkkynen, S., Buist, G., Kunji, E., Kok, J., Poolman, B., Venema, G. \& Haandrikman, A. (1993). Genetic and biochemical character- 
ization of the oligopeptide transport system of Lactococcus lactis. J Bacteriol 175, 7523-7532.

Urbach, G. (1995). Contribution of lactic acid bacteria to flavour compound formation in dairy products. Int Dairy J 5, 877-903.

Wang, H., Yu, W., Coolbear, T., O’Sullivan, D. \& McKay, L. L. (1998). A deficiency in aspartate biosynthesis in Lactococcus lactis subsp. lactis C2 causes slow milk coagulation. Appl Environ Microbiol 64, 1673-1679.

Wang, H., O'Sullivan, D. J., Baldwin, K. A. \& McKay, L. L. (2000). Cloning, sequencing, and expression of the pyruvate carboxylase gene in Lactococcus lactis subsp. lactis C2. Appl Environ Microbiol 66, 1223-1227.

Xing, R. \& Whitman, W. B. (1992). Characterization of amino acid aminotransferases of Methanococcus aeolicus. J Bacteriol 174, $541-548$.
Yu, W., Gilles, K., Kondo, J. K., Broadbent, J. R. \& McKay, L. L. (1996). Loss of plasmid-mediated oligopeptide transport system in lactococci : another reason for slow milk coagulation. Plasmid 35, 145-155.

Yvon, M., Thirouin, S., Rijnen, L., Fromentier, D. \& Gripon, J. C. (1997). An aminotransferase from Lactococcus lactis initiates conversion of amino acids to cheese flavor compounds. Appl Environ Microbiol 63, 414-419.

Yvon, M., Chambellon, E., Bolotin, A. \& Roudot-Algaron, F. (2000). Characterization and role of the branched-chain aminotransferase $(\mathrm{BcaT})$ isolated from Lactococcus lactis subsp. cremoris NCDO 763. Appl Environ Microbiol 66, 571-577.

Received 21 June 2000; revised 20 September 2000; accepted 27 September 2000. 